\title{
O jogo The Sims como tela de projeção e elaboração de experiências
}

\section{Game The Sims like projection screen and elaborations of experiences}

\section{Juego The Sims como pantalla de proyección y elaboración de experiencias}

\section{J éssica Maíres Severino Mota*}

Universidade Federal de São J oão del- Rei, São J oão del - Rei, Brasil

\author{
Marcos Vinícius Thomaz** \\ Universidade Federal de São J oão del- Rei, São J oão del - Rei, Brasil
}

Maria de Fátima Aranha de Queiroz e Melo***

Universidade Federal de São J oão del- Rei, São J oão del - Rei, Brasil

\begin{abstract}
RESUMO
Articulando a Psicologia com o trabalho de experimentação digital, investigamos a utilização do jogo de simulação virtual The Sims como tela projetiva, buscando seguir a elaboração de vivências de um grupo de préadolescentes moradores de uma casa abrigo. Para tanto, foram realizadas, ao longo de 2013, oficinas na Lan House de uma universidade com o intuito de compreender como os participantes utilizavam o jogo para ressignificar os fatos de suas vidas. Utilizando como suporte teórico metodológico a Teoria Ator-Rede, seguimos, no jogo, as falas e os movimentos dos participantes para montar um registro que nos permitisse levantar hipóteses sobre a maneira como se projetavam nos cenários montados.
\end{abstract}

Palavra-chave: teoria ator-rede, casa lar, tela de projeção.

\begin{abstract}
Linking Psychology with the work of digital experimentation, we investigated the use of virtual simulation game The Sims as projective screen, seeking to follow the elaboration of the experiences of a group of pre-adolescents living in a shelter home. Lan House workshops were carried out throughout 2013 in a university in order to understand how the participants used the game to resignify the facts of their lives. Using Actor-Network Theory as theoretical and methodological support, we followed, in the game, narratives and movements of the participants to set a record that would allow us to make hypotheses about the way the players were projected on mounted scenarios. Keywords: actor-network theory, shelter home, projection screen.
\end{abstract}




\begin{abstract}
RESUMEN
Hemos establecido una conexión entre la Psicología y el trabajo de experimentación digital para investigar el uso de juego de simulación virtual de Los Sims como pantalla proyectiva, tratando de seguir elaboración de las experiencias de un grupo de pre-adolescentes que viven en una casa de acogida. Se llevaron a cabo, a lo largo de 2013, talleres en una Lan House de la universidad con el fin de entender cómo los participantes utilizan el juego para replantear los hechos de sus vidas. Se utilizó la Teoría del ActorRed como un soporte teórico y metodológico, cuando seguimos en el juego, las líneas y los movimientos de los participantes para montar un record que nos permitió hacer hipótesis sobre la proyección de los actores y escenarios montados.
\end{abstract}

Palabras clave: teoría del actor-red, casa de acogida, pantalla de proyección.

\title{
1 Introdução
}

As redes são misturas complexas de elementos que produzem efeitos variados. No afã de mapear a rede que fez emergir o fenômeno que acompanhamos, apresentamos neste artigo os cenários e os atores que dela fizeram parte, as estratégias utilizadas nesta busca e algumas reflexões sobre o que a pesquisa fez fazer.

\section{Cenários e atores}

\section{A Lan house}

Desde 2008, o Projeto Lan House configura-se como um projeto de extensão com interface na pesquisa, em um espaço físico anexo à Brinquedoteca, onde se encontram computadores e acessórios como fones de ouvido, câmeras e impressoras. Entendemos a Lan House como um grande dispositivo ${ }^{1}$ composto de espaço físico, móveis, pautas institucionais, pessoas, máquinas, softwares, ela própria resultado de redes também heterogêneas. As atividades mantidas na Lan House atendem aos diversos públicos, como grupos de egressos da APAE, um grupo de idosos, outro constituído por adultos funcionários terceirizados da própria universidade e grupos de crianças provenientes de duas Casas Lares que têm parcerias com projetos desenvolvidos pela universidade. As oficinas realizadas na Lan House constituem-se como um espaço de experimentação digital que ocorre de maneiras diversas com a mediação de aplicativos como reprodutores de mídias e áudio, redes sociais e jogos diversos que são selecionados pelos próprios participantes com a ajuda dos estagiários do curso de Psicologia. O fato de termos estudantes de Psicologia desenvolvendo este projeto é o que proporciona uma diferenciação das atividades realizadas em relação a um processo de 
inclusão digital proposto em uma aula de informática, pois os estagiários assumem o papel de mediadores, podendo assim voltar seu olhar para os efeitos que estas atividades produzem na reelaboração das vivências destes participantes e na necessidade de efetivarem e expressarem seu pertencimento social. Por esta razão, ao invés de inclusão digital, preferimos utilizar expressões como experimentação digital e mediação digital para nomear a proposta. A ideia de mediação remete à possibilidade de produzir efeitos em rede, de estar "entre", de interferir, de afetar e deixar-se afetar, entendendo que o processo ocorrido nas oficinas não está restrito a um que inclui e um outro que se deixa incluir de forma unilateral e passiva, mas atinge a todos os envolvidos. As atividades realizadas na Lan House são desenvolvidas em forma de oficinas que têm como objetivo trabalhar a ludicidade e a sua conexão com as vivências de um outro, podendo ser esse outro um participante do grupo, um estagiário, ou um software.

O trabalho em questão foi desenvolvido junto a um público constituído por jovens moradores de uma casa abrigo, denominada Casa Lar. As crianças e adolescentes das duas Casas Lares já eram freqüentadoras da Brinquedoteca desde 2009, por solicitação dos respectivos gestores e com a autorização da figura de seu/sua tutor (a) legal. Durante as visitas à Brinquedoteca, manifestavam interesse na utilização dos computadores em rede que compunham a Lan House. Como pré-adolescentes de nossa época, explicitavam, em suas falas, o desejo de ter acesso às tecnologias oferecidas pelos games e outras "janelas" para o mundo e nos solicitavam a oportunidade de participar das oficinas da Lan House. Foi com o propósito de atendê-las que as oficinas lúdicas foram organizadas, tendo como mediadores os estagiários do curso de psicologia.

\section{As Casas Lares}

Por abrigos entendemos instituições que acolhem menores que se encontram em situação de risco social e estão sob a tutela do Estado; protegidos por uma medida legitimada pelo Estatuto da Criança e do Adolescente. De acordo com Cavalcante, Magalhães e Pontes (2007), o termo abrigo pode ser entendido como esconderijo, recanto, moradia, ninho ou acolhida. Contrariando a expectativa dessa definição, a retirada destes jovens de seu meio familiar pode significar menos um abrigo e mais um isolamento, já que estas instituições ainda reproduzem, em algumas de suas práticas, características de instituições totais. Há, portanto, uma ambivalência nos efeitos produzidos pelo abrigamento: quando o Conselho Tutelar resgata essas crianças e adolescentes de situações de risco como abandono, maus tratos e violência e os afasta de seus responsáveis para garantir as condições básicas para seu desenvolvimento, 
também os expõe a outras situações que podem lhes causar danos, como a ruptura com seu meio social, o afastamento de seus familiares e a segregação. Para evitar tais danos, o Estatuto da Criança e Adolescente (ECA) desenvolveu diretrizes voltadas para o tipo de acolhimento que estes menores devem receber, bem como para o trabalho a ser realizado com seus familiares para que voltem para suas famílias o mais rápido quanto possível (Lei n. 8.069, 2006). Enquanto isso não acontece, os abrigos funcionam como lares de passagem que deveriam ter um caráter provisório, embora o período de permanência acabe por se estender para além do previsto, produzindo um sentimento de indefinição (quem sou eu aqui?) e imprevisibilidade (o que vai acontecer comigo?), naqueles que se encontram tutelados.

Segundo Parreira e Justo (2005), este público tem grande demanda de intervenções psicossociais, devido a situação de institucionalização em que vive, o que pode afetar a construção da identidade e deixálos em uma situação de mais vulnerabilidade. Muitos daqueles que são alvo dos projetos socioassistenciais, freqüentadores dos projetos desenvolvidos pela universidade, vêm marcados por histórias que preferem não contar, demandando atenção e acolhimento. Ainda que tenham o amparo das condições de cuidado oferecidas pelas Casas Lares, anseiam por uma volta ao lar, a um convívio de família mesmo aquela que os negligenciou - que Ihes permita dizer "quem são" e "de onde vêm", sem a homogeneização de um coletivo amorfo. Ao fazerem a mediação do grupo de pré-adolescentes com as máquinas da Lan House e seus aplicativos, os estagiários de Psicologia buscaram acompanhá-los em seus movimentos de subjetivação, oferecendo-se como elementos responsivos de quem podiam ter um olhar de atenção e cuidado. Por subjetivação, entendemos a capacidade de diferenciação a partir das várias conexões que estabelecemos com o outro. Ir ao Campus da Universidade, frequentar a Lan house, conviver com outras pessoas fora do âmbito da Casa Lar, experimentar computadores, softwares e o acesso à Internet se constituiu uma rede de atores que funcionou como mais um elemento subjetivador dos participantes das oficinas.

\section{O jogo The Sims}

O jogo de simulação virtual The Sims foi lançado no ano 2000 pela empresa Electronic Arts. Trata-se de um espaço virtual onde o jogador pode criar e controlar seus avatares ${ }^{2}$, podendo desempenhar assim qualquer tipo de função no jogo, desde construir e decorar a casa de seu personagem até decidir quais tipos de relações este vai estabelecer com os demais (Krüger \& Cruz, 2004). O jogo é composto por cenários, que são os módulos de construção dos personagens em que o jogador pode personalizar seus avatares, o módulo de 
construção da casa e o módulo de compras, incluindo móveis para a casa, roupas e acessórios. As atividades desenvolvidas no decorrer do jogo vão das mais básicas como dormir, comer e tomar banho, até funções sociais como ir a festas, ao trabalho e à escola. No módulo de construção do personagem, há a opção de escolher um personagem já determinado pelo jogo ou construir seu próprio avatar usando os recursos que permitem ao jogador determinar o formato do nariz, olhos e boca, escolher roupas apropriadas para variadas situações sociais, além de poder escolher acessórios como óculos, brincos, relógios, entre outros.

Os jogos de simulação ${ }^{3}$ virtual são um grande atrativo para os jovens, pois possibilitam a criação de novos mundos pelos quais estes se tornam responsáveis, além de não apresentarem um final já prédeterminado. Os jogadores devem completar o jogo usando sua imaginação e os recursos que o jogo oferece. De acordo com Huizinga (1993), jogo é "aquilo que você faz quando está livre para fazer o que desejar" e, dentro do contexto da ludicidade, o jogo The Sims apresenta características que são capazes de absorver o jogador em uma atmosfera que possibilita, ao mesmo tempo, uma fuga da realidade e uma experimentação de novas realidades que podem ser construídas e controladas. Num jogo de simulação, os jogadores, através de seus avatares, se lançam nas situações provocadas/sugeridas pelo jogo e fazem de conta que as vivem na tela, sem terem que se deslocar espacialmente. Rains (como citada por Colen \& Queiroz e Melo, 2010) não vê os games como uma simples forma de entretenimento, uma vez que outros efeitos podem ser sentidos. Os jogos de simulação podem proporcionar ao jogador a experimentação de uma existência paralela à vida real, assim como outras identidades e possibilidades de interação. Jogos de simulação nas telas do computador estão relacionados a versões de situações e objetos baseados em temas que de fato existem na realidade, diferenciando-se da simulação de outros tipos de jogos, por apresentarem múltiplas narrativas que são construídas com os recursos disponibilizados pelo jogo. Este é um ponto a considerar no The Sims, visto que a proximidade dos elementos do jogo com a vida diária dos jogadores permite recriar na tela situações do seu cotidiano e modificá-las de acordo com seus desejos (Krüger e Cruz, 2001). O jogo como artefato também é fruto de uma rede e não se encontra fechado em suas possibilidades. The Sims, no contato com seus usuários, já passou por inúmeras versões para tornar-se cada vez mais diferenciado e sintonizado com as demandas da ludicidade contemporânea, tanto em termos de suas funcionalidades quanto em relação à diversidade do que hoje podemos chamar de "família", casa e outras relações. $O$ jogo de projeções ocorre nesse encontro entre as várias narrativas que se cruzam do que os participantes trazem das suas histórias pessoais, da sua permanência na Casa Lar, das tramas 
feitas nas oficinas com companheiros e coordenadores e das possibilidades oferecidas pelo jogo. Ao longo das oficinas realizadas dentro do Projeto Lan House, pudemos perceber o aumento da adesão dos participantes ao jogo e como estes o utilizavam para experimentar estratégias e para fazer aproximações das experiências que tinham dificuldade de verbalizar.

\section{A projeção}

O termo projeção, bastante utilizado na Psicologia, não é aqui tomado como exclusivo da Psicanálise, nem necessariamente ligado à suposição de um inconsciente, agindo como um mecanismo de defesa. Foi utilizado por autores de outras áreas, assim como Shakespeare (como citado por Werlang, Lima e Fensterseifer, 2006), autor que identificou as formas ambíguas e sugestivas das nuvens, percebendo que a elas eram atribuídos significados diferentes de acordo com a percepção de cada pessoa. Nenhuma pessoa via a mesma imagem, levando a crer que os conteúdos observados provinham das experiências pessoais de cada uma. Na neurologia, a projeção aparece como um mecanismo que funciona quando um evento é deslocado do meio interno para o externo, ligando-se a respostas do organismo. Quando são apresentados estímulos sensoriais que se conectam às regiões do Sistema Nervoso onde estão alocadas impressões anteriormente percebidas, o organismo responde novamente a estes novos estímulos que evocam lembranças passadas (Fonseca \& Mariano, 2008). Jung (como citado por Pereira, 2007) também deixa sua contribuição sobre a projeção, conceituando-a como um mecanismo psicológico geral que expulsa conteúdos do sujeito jogando-os sobre o objeto, com cargas de afeto que podem ser tanto positivas quanto negativas, indicando um estado de fusão entre sujeito e objeto. Buscamos ultrapassar as fronteiras que aprisionam o conceito de projeção a uma só versão, expandindo-o para outros domínios e operando com ele para compreender o movimento dos jogadores.

A projeção, pensada a partir da Teoria Ator-Rede, segue a lógica das conexões. Um retro projetor lança para uma tela, através de um sistema de lentes, uma imagem que se atualiza e se valida nesse lançamento/compartilhamento. As imagens que nos habitam são construídas na experiência que temos do mundo e não fruto de uma interioridade prévia. Singularizadas nas mesclas feitas por cada sujeito, seriam os vestígios dos vários outros que, em rede, atuam em cada um, projetadas como se fossem próprias. Um jogo de simulação propõe este movimento em que imagens e sentidos a elas atribuídos por cada jogador se projetam e se fundem com personagens e cenários nas imagens que fazem parte do jogo, numa ação performática. 
Para tornar-se um sujeito, este é atravessado pelos outros que nele atuam e the deixam marcas, traços, efeitos. Os modos de subjetivação se remetem aqui a um sujeito que se constitui como um laboratório de misturas e que tem a alteridade como ingrediente principal. Quando os participantes das oficinas projetavam, nas cenas do jogo, imagens das experiências vividas, produziam nelas torções que as faziam diferir do que eram antes, mas, ao mesmo tempo, manter a semelhança com o vivido. Nesse jogo, podiam ensaiar/testar/reelaborar outras performances para suas histórias.

\section{Estratégias utilizadas}

Visto o caráter dinâmico dos jogos eletrônicos, foi necessário utilizarmos estratégias que nos permitissem adentrar no universo tanto do jogo quanto dos jogadores, buscando entender quais os caminhos que foram traçados durante a construção do jogo e como os jogadores se ligavam aos dispositivos ${ }^{4}$ da máquina possibilitando as projeções.

Quando adentramos nessa rede, nos estabelecemos como mais um ponto dela, não fomos observadores passivos, nos apresentamos como atores e passamos também a fazer conexões e a estabelecer vínculos. Para Latour (2000, como citado por Arendt, Ferreira, Moraes, \& Tsallis, 2006), um vínculo "designa o que comove e coloca em movimento, fora da antiga tentativa de definir a ação a partir do dilema da determinação versus liberdade". O vínculo construído com os participantes das oficinas foi o que nos possibilitou ocupar diferentes papeis, ora como potenciais cuidadores, ora como companheiros mais experientes de quem eram demandadas orientações, ou ainda aqueles com quem conversavam e para quem contavam seus "causos".

A nossa inserção na rede não se limitava a observar e acompanhar os jogadores, pois construíamos as oficinas junto com eles, passávamos a conhecer mais sobre sua história e sobre as redes às quais já estavam ligados. Mergulhamos no universo do jogo, fazendo nossos próprios jogos para entender a maneira como o software funcionava em suas várias etapas e como se apresentava aos jogadores. Buscamos nos tornar mediadores das atividades realizadas, agenciando as multiplicidades existentes entre humanos e não humanos ${ }^{5}$, além de garantir um espaço de elaboração das experiências vivenciadas no jogo (Kastrup, 2012).

Entendendo que na rede de relações, cada ator não apenas a modifica, mas é também por ela modificado, o mergulho nas oficinas nos permitiu pensar também sobre os processos que ali aconteciam, sobre as possibilidades de experimentação, seus elementos, seus limites e suas barreiras. A primeira barreira com que nos demos 
conta nas oficinas se relacionava com o modelo de família adotado pelo jogo. Por mais que os jogadores insistissem em construir uma família sem figuras parentais ou maiores legalmente capacitados para exercer a responsabilidade de cuidar, o tipo de programação usada pelo aplicativo não permitia a criação de uma família formada apenas por adolescentes e crianças - estratégia tentada por vários dos jogadores - partindo da premissa de que menores são dependentes de adultos. Outra limitação verificada foi a impossibilidade de os personagens explorarem outros ambientes para além da casa construída, situação próxima àquela em que se encontravam, em que a maior parte de suas atividades se reduzia ao ambiente institucional da casa. Foram buscadas atualizações e versões mais recentes do jogo em que estas limitações já haviam sido superadas. Nas versões mais recentes, adolescentes em transição à vida adulta, nomeados como "jovens adultos", já possuíam autonomia para assumir uma casa, sem a necessidade de figuras a serem tomadas como tutoras ou responsáveis. As barreiras que limitavam as ações dos jogadores ao ambiente doméstico também foram superadas com a atualização. Os avatares passaram a ter a possibilidade de transitar por outros espaços do bairro e cidade, como casas de vizinhos, parques, praças, clubes, escolas, bibliotecas, academias, boates, entre outros elementos, possibilitando novas experimentações.

\section{As oficinas como dispositivos}

As atividades realizadas na Lan House são desenvolvidas em forma de oficinas que têm como objetivo trabalhar a ludicidade mediada por humanos e não humanos. Por oficinas, consideramos os trabalhos estruturados em grupo com um foco central, o que leva a processos de elaboração de experiências compartilhadas, sendo possível elaborá-las através de informação e de transferências positivas dentro do grupo (Afonso, 2002).

As oficinas da Lan House ocorreram semanalmente com a duração de duas horas, tendo como objetivo trabalhar temáticas escolhidas pelos participantes juntamente com os estagiários. Foi no contexto da escolha de jogos que eram do interesse dos participantes que o jogo de simulação virtual The Sims se destacou entre aqueles que haviam sido instalados pelos estagiários e rapidamente conquistou 0 interesse do grupo que passou a jogá-lo em todas as oficinas.

A opção de jogar o The Sims era livre, nem todos jogavam e aqueles que o faziam com mais freqüência ainda realizavam outras atividades simultâneas, como ouvir músicas e baixar fotos. Durante as oficinas, os participantes também aprendiam funções relacionadas a outras utilidades do computador como criar pastas, salvar links, passar antivírus, realizar pesquisas na internet, fazer montagem de vídeos e utilização de programas de edição de imagem. Durante estas oficinas, 
eram registradas, em um diário de campo, anotações sobre as movimentações dos participantes, de como se dava sua adesão ao jogo e consecutivamente seus movimentos neste, assim como também quais outras atividades competiam com o jogo na eleição da atividade a ser realizada durante os encontros. Cada participante tinha uma ficha individual onde era registrado um histórico das suas ações.

As oficinas compostas pelos jogos, jogadores, softwares, estagiários, pautas institucionais e outros arranjos variados passaram elas mesmas a assumir o papel de um dispositivo, tal como definimos na nota 1 . O grupo de jovens era constituído de dez participantes, sendo sete meninas e três meninos, com idades entre 8 e 14 anos. Especificamente com este grupo, além da experimentação digital, surgiram questões em torno da dificuldade de estabelecer vínculos ${ }^{6} \mathrm{e}$ do sentimento de exclusão social ${ }^{7}$ devido à situação de abrigamento.

\section{Seguindo os Sims}

Os momentos do jogo

Dentre as observações feitas, percebemos uma maior adesão das meninas ao The Sims, embora os meninos também se aventurassem no jogo, com objetivos diferentes. Enquanto as meninas gastavam a maior parte do tempo das oficinas criando os avatares e montando suas casas, os meninos iam direto para o jogo, algumas vezes tomando até personagens prontos e focando mais na jogabilidade ${ }^{8}$. As meninas ficavam mais centradas na criação do avatares, desde sua construção física até seus acessórios, podendo-se perceber um movimento exploratório onde as jogadoras passavam por cada função do jogo experimentando todas as suas possibilidades. Ao dirigirmos um olhar mais atento para este interesse das meninas na criação dos avatares, percebemos que este movimento de exploração se repetia entre os participantes das oficinas quando jogavam jogos online, principalmente as meninas, que davam preferência aos jogos em que elas podiam construir personagens, montá-los e vesti-los. Elas justificavam essa preferência dizendo que, no jogo, podiam escolher quais roupas iriam vestir, pois na casa abrigo não havia essa possibilidade. Neste primeiro momento, pudemos ver o jogo como um espaço onde os jogadores poderiam compensar certas condições de sua realidade, realizando, no faz de conta, ações simples das quais eram privados em seu cotidiano. Segundo Vygotsky (1991), o jogo de faz-de-conta traz essa possibilidade de a criança reviver e elaborar situações que Ihe causaram algum tipo de impressão, dando-lhe a chance de reorganizar as experiências para compreendê-las melhor, ou até mesmo ressignificar momentos que lhe causaram forte 
impressão. No jogo de simulação, isto ocorre de maneira desapreensiva, o que permite ao jogador uma expressão protegida de censuras com a liberdade de recriar cenas, sem que isto the cause emoções com a mesma intensidade.

Partindo destas primeiras observações, nos foi possível traçar os caminhos feitos pelos jogadores. No começo das oficinas, observamos que os jogadores expunham, na tela do jogo, elementos da realidade vivenciada dentro da Casa Lar, reproduzindo espaços e relações da rede que Ihes abrigava naquele momento. As dinâmicas dos jogos se apresentavam muito semelhantes, com a construção de casas com espaços coletivos onde os quartos eram compartilhados e divididos por gênero: havia o quarto das meninas e o quarto dos meninos, ambos com várias camas. Os avatares também eram uma representação dos colegas de quarto da Casa Lar. Os jogadores não se preocupavam muito em arrumar emprego no jogo e nem conseguiam administrar bem o dinheiro. A preocupação era totalmente voltada para as necessidades sociais dos avatares, deixando, em segundo plano, suas necessidades físicas, como comer e dormir. Como consequência, ocorriam muitas "mortes" no jogo, devido à falta de cuidado com os personagens, fato que ensejou, em alguns momentos, um debate sobre a morte e possibilitou aos jogadores falar de suas experiências de luto pelas pessoas que perderam e de como se sentiam em relação a essas faltas. Falar do que haviam perdido era narrar um pouco da sua própria realidade, visto que mantinham um contato social restrito, por terem a rotina limitada entre a Casa Lar, a escola e as idas para as oficinas na Lan House ou na Brinquedoteca. Este primeiro momento também refletia um movimento de exploração do jogo, de forma que os jogadores experimentavam todas as roupas e acessórios, passavam por todas as funções do jogo, como compra de móveis e construção das casas até esgotarem o dinheiro que cada avatar recebia ao ser criado. Quando este recurso acabava, os jogadores preferiam começar um novo jogo, ao invés de prosseguir no mesmo.

Em outro momento, quando os jogadores passaram a assumir papeis mais estáveis no jogo, uma das participantes, a mais velha do grupo, passou a representar o papel de mãe, sendo as filhas suas colegas de quarto dentro da casa. As participantes mais novas, reciprocamente, aceitaram o papel de mãe incorporado pela jogadora mais velha e se colocaram no papel de filhas, reproduzindo essa mesma dinâmica em seus próprios jogos. Nas oficinas, estas meninas sentavam sempre em máquinas próximas, de forma que a mais velha interferia constantemente na construção dos jogos das demais; e estas, por sua vez, tinham o costume de pedir ajuda à mais velha. Assim, mesmo este não sendo um jogo coletivo, todas as meninas do grupo passaram a estabelecer uma nova rede em que representavam uma família que se baseava no jogo de papeis encenados pelas jogadoras 
dentro da casa lar. Entre as conversas realizadas com o grupo, pudemos perceber que, em muitos momentos, ficava a cargo das moradoras mais velhas "cuidar" das mais novas. Este padrão não era estabelecido explicitamente, mas se desenvolvia durante a convivência dos moradores dentro da casa. A jogadora mais velha se sentia no papel de mãe dos mais novos, não só no jogo, mais também não seu dia-a-dia ao cuidar dos demais, separando brigas entre eles, pedindo silêncio quando necessário e dando broncas quando faziam bagunça.

Um terceiro momento que pudemos identificar foi quando, ao longo das oficinas, todos os jogadores experimentaram os papeis de mães e pais. Até mesmo os jogadores mais novos que se colocavam apenas no papel de filhos passaram a construir suas próprias famílias, constituídas de filhos e companheiros. Os avatares que representavam os filhos recebiam nomes de parentes das famílias dos jogadores na vida real, enquanto os avatares que representavam os companheiros recebiam nomes, segundo os jogadores, de colegas da escola. Nessa etapa, foi possível observar uma maior responsabilidade por parte dos participantes em relação a algumas funções do jogo, como a de cuidar das necessidades básicas dos avatares de forma mais equilibrada e manifestar uma preocupação em arrumar um emprego para poder ajudar no sustento da família. A esta altura, percebemos uma inversão no conteúdo das projeções feitas no jogo: ao invés de projetar conteúdos da realidade vivenciada na casa lar, os jogadores passaram a projetar elementos que desejavam para sua vida no futuro, seus desejos de formação de família e de cuidado com o outro.

Em um último momento, observamos que os jogadores passaram a projetar no jogo membros da família da qual foram tirados, passando a resgatar pais, mães e irmãos que, na maioria das vezes, não viam há muito tempo. Percebemos que buscavam retratar seus parentes o mais fielmente possível, integrando, na tela do jogo, seus desejos e fantasias em relação às suas famílias reais, expressando seus desejos para o futuro e representando a si mesmos como adultos com suas próprias famílias. Durante as conversas que ocorriam nas oficinas, perguntamos a uma das jogadoras, a mais velha do grupo, quem eram aqueles avatares representados ali e ela nos relatou que os personagens mais velhos eram seus pais. Disse-nos que ela visitava o pai em alguns fins de semana, mas a mãe havia falecido havia alguns anos. A família construída no jogo ainda era composta por ela, já adulta, o marido e dois filhos. Enquanto nos relatava seus personagens, ela falava da mãe, das lembranças que tinha dela, de como ela se parecia, do que gostava e do que mais sentia falta nela; relatou-nos também como queria ser quando fosse mãe, como seria ter filhos e uma casa que fosse só sua. Outra jogadora explorava na tela do jogo as possibilidades de exercer carreira como policial que 
dizia ser seu sonho. Uma outra reviveu no jogo a própria experiência de criança abrigada, quando um personagem de seu jogo, o avatar de uma criança, foi levado pela assistência social, retirado da família por não ter sido bem cuidado. Neste momento, todos os participantes voltaram a atenção para aquele jogo e começaram a discutir o fato, imaginando como seria a Casa Lar dos Sims e de como era difícil cuidar de uma criança.

Os meninos passavam mais rapidamente pelo jogo, dando preferência para jogos de ação como os de corrida ou de lutas. Enquanto jogavam, também exploravam diversas possibilidades do jogo, desde arrumar um emprego de ladrão, levantando a questão sobre o que seria certo ou errado segundo as regras do jogo, até a compra de itens que eles não possuíam na Casa Lar, como um bom aparelho de som e até mesmo um carro.

Foi-nos possível também perceber nossos próprios movimentos de projeção, pois, ao jogarmos, também tivemos a tendência de reproduzir na tela elementos do nosso cotidiano: nomeávamos os personagens com nomes de pessoas conhecidas e também brincávamos de assumir papeis que se diferenciavam da nossa vida real, como experimentar uma profissão diferente daquela que já estava traçada. Este processo foi de grande importância para a compreensão dos movimentos dos participantes no jogo e também para uma maior interação destes com os estagiários. Os participantes das oficinas nos perguntavam sobre nossas vidas, nome dos nossos pais e irmãos e colocavam esses nomes nos seus jogos, incluindo-nos no universo criado por eles na tela. Algumas dessas perguntas eram sentidas como uma forma de aproximação, para saber como eram as nossas vidas e compará-las com as suas. Em uma dessas situações, ao perguntarem onde morávamos e com quem morávamos, ficaram surpresos ao saber que, assim como eles, não estávamos mais com nossos pais. Compararam as nossas repúblicas com a sua atual situação, constatando que, em ambos os casos, era preciso morar com pessoas que não eram conhecidas e dividir espaços. Apesar das diferenças, esta aproximação os ajudava a construir um vínculo com aqueles que passavam a fazer parte das suas vidas como referências mais estáveis em relação àquelas oferecidas pelos funcionários da Casa Lar.

O que ficou da pesquisa: articulações

Ao percorrermos os caminhos trilhados pelos jogadores percebemos que, para compreendê-los, foi preciso penetrarmos na rede e criar vínculos com os participantes das oficinas, deixando-nos afetar por suas histórias. O jogo se constituiu como mais um plug-in ${ }^{9}$, um acesso que fez crescer as possibilidades de ação dos jogadores, permitindo restaurar, ainda que imaginariamente, alguns vínculos 
que foram rompidos ou que eram muito idealizados, fossem esses prazerosos ou dolorosos. Podemos dizer que o jogo The Sims funcionou como um mediador neste processo, produzindo diferenciações em relação ao modo como iniciaram as oficinas. No jogo, os participantes puderam experimentar diferentes configurações de família na maneira como cuidavam e eram cuidados ${ }^{10}$. A esfera do cuidado não foi sentida como uma preocupação nas primeiras explorações do jogo, ocasionando a "morte" dos avatares. A situação de estarem abrigados em espaços onde todos os pertences eram compartilhados marcou a necessidade de experimentarem escolhas variadas, sem a imposição do que e como deveriam usar em seus cotidianos. Ao consensarem a atribuição do papel de "mãe" às meninas mais velhas e de filhas às mais novas, as participantes do grupo tomaram aquelas que eram suas referências imediatas num convívio em curso, passando cada uma delas a experimentar esse papel, fato que nos pareceu estar referido à possibilidade de exercitar o cuidado de que demandavam. A projeção em uma situação familiar futura trouxe o desejo de pertencimento e de cuidado com o outro e, num momento posterior, as imagens dos membros da família original puderam aparecer de uma maneira menos dolorosa, sem suscitar toda a intensidade de uma perda e/ou abandono que eram pontos de evitação/omissão nas falas trazidas.

Ao utilizarmos o jogo The Sims como tela projetiva, propusemos uma outra performance para este dispositivo, de forma que pudesse ser apropriado pelos jogadores em suas várias configurações. Segundo Mol (2007, como citada por Pedro, 2008), a noção de performance está ligada a uma realidade que é construída ao longo de uma prática. Tendo o jogo como um dispositivo performático, podemos percebê-lo como aquilo que cada jogador faz dele que se transforma mediante as estratégias utilizadas por cada jogador: por mais que a programação dos softwares seja a mesma, cada jogo é único. Ao longo das oficinas, essa prática nos ofereceu versões múltiplas de um mesmo objeto, fazendo-nos perceber como um jogo de simulação virtual pode ganhar aspectos de uma tela projetiva ${ }^{11}$. No jogo, é possível provocar narrativas menos apreensivas, sem o desencadear de fatores ansiogênicos, pois, quando usa o The Sims, o jogador se coloca em uma posição de criador e controlador de experiências vividas na tela e tem total domínio das narrativas que vão se construindo ao longo do jogo, como se estivesse contando uma história que, ao longo das oficinas, se entrelaça com sua própria história de vida, moldando-a e escrevendo seus capítulos futuros (Braga, 2009). Os avatares aparecem como elementos híbridos de humanos e não-humanos, mediadores de dois mundos, o real e o imaginário. Este ser hibrido é dotado de uma grande mobilidade, podendo viver e reviver situações a partir de perspectivas diferentes, 
dando aos jogadores a chance de recriar suas vivências na tela do jogo e exercer papeis diferentes (Colen \& Queiroz e Melo, 2010).

Podemos entender a funcionalidade do The Sims como tela projetiva na medida em que vemos os movimentos dos jogadores liberando emoções e encontrando alívio para as situações vivenciadas (Erikson, 1971, como citado por Krüger \& Cruz, 2004). Piaget (1978) também explicita essa função dos jogos, evidenciando a transposição simbólica que ocorre ao jogar:

na presença de situações penosas ou desagradáveis, a criança pode compensá-las, como precedentemente, ou então aceitálas; mas, nesse último caso, procura revivê-las mediante uma transposição simbólica (p. 172).

Dentro deste contexto, entendemos que o conceito de projeção não necessariamente se constitui como um processo advindo do inconsciente, tal como postulado pela psicanálise. Como vemos em Tarde (2003, como citado por Pereira, 2007), nossa psique pode assemelhar-se a uma sociedade em que os elementos existem de forma articulada, sem estar sujeitos às subdivisões do inconsciente e consciente. Como alternativa para pensar nossa psique, Tarde a propõe como um conjunto de mônadas ${ }^{12}$. Com o modelo de uma psique em rede, as mônadas dirigentes - que comandam nossas ações - e as mônadas auxiliares - que se apresentam de acordo com as situações - estariam se revezando na maneira como nos conduzimos. Nesta perspectiva, os processos de projeção não precisariam estar alocados num suposto inconsciente e os conteúdos projetados não estariam reprimidos, mas apenas em um segundo plano, passando à cena principal à medida que as narrativas vão se construindo na tela do jogo.

Ao longo da pesquisa, pudemos ainda destacar os processos de tradução que ocorreram, tanto do próprio conceito de projeção, como dos dispositivos do jogo The Sims. Conceito caro à Teoria Ator-Rede, a tradução é a apropriação que cada ator faz da rede e dentro desta rede:

Traduzir significa atribuir a um elemento de uma rede um papel a ser representado por ele; significa emprestar-lhe uma identidade, prática que é realizada por todos os elementos de uma rede, em um movimento mútuo e contínuo, a partir dos desejos, expectativas e/ou interesses de cada um dos tradutores (Benakouche, 2001, p.54, como citado por Pedro, 2008).

Seguindo esta lógica, percebemos que todos os elementos da rede se traduziram: os participantes das oficinas puderam elaborar suas 
experiências de vida, o jogo ganhou novos significados para o público específico que dele fez uso, os pesquisadores se acrescentaram de novos conhecimentos, o conceito de projeção foi ampliado para outras áreas de conhecimento e não ficou aprisionado nas fronteiras da psicanálise.

Outro conceito da Teoria Ator-Rede que trazemos para nossa reflexão é o principio de simetria. Operando de forma simétrica quando realizamos um estudo, todos os atores, humanos e não humanos têm as mesmas possibilidades de mediação e interferência em um contexto. Tanto a Lan house como um amplo dispositivo, os estagiários de Psicologia, assim como as máquinas e seus dispositivos - redes conectadas a outras redes - se tornaram plug-ins que possibilitaram a transformação da tela do jogo em um espaço de projeção (Maia e Serafim, 2011). Entendemos que o desenvolvimento do jogo The Sims, ao longo das oficinas da Lan House, foi um dispositivo que possibilitou um espaço de reelaboração de experiências dos jogadores, de forma que estes puderam vivenciar e expressar, por meio do jogo, a realidade de ser uma criança abrigada, de dividir espaços com vários moradores na mesma casa, de ter que cuidar das crianças menores, de demandar e de exercer cuidados. Também Ihes foi possível idealizar projeções futuras, como ter uma casa só sua, ter o emprego dos sonhos, ter filhos e, por fim, criar momentos reparadores como estar com parentes com os quais não convivem mais e, ao final deste processo, compartilhar suas histórias que puderam ser contadas diversas vezes, com cenas variadas, histórias das quais agora nós e todos os mediadores fazemos parte.

\section{Referências}

Afonso, L. (2002). Oficinas em dinâmica de grupo: Um método de intervenção psicossocial ( $3^{a}$ ed). Belo Horizonte: Edições do Campo Social.

Agamben, G. (2009). O que é um dispositivo? In: G. Agamben (2009). O que é o contemporâneo e outros ensaios (V.N. Honesko, Trad.) (pp. 26-51). Chapecó: Argos.

Arendt, R. J., Ferreira, A. A. L., Moraes, M. O., \& Tsallis, A. C. (2006). O que nós psicólogos podemos aprender com a Teoria AtorRede? (pp. 57-86). Interações. São Paulo. Recuperado em 25 de Abril, 2013, de http://www.metaclinica.com.br/pdfs/O\% 20que\% 20nos\% 20psic ologos\% 20podemos\% 20aprender.pdf

Benakouche, T. (2001). Duas culturas, três culturas... ou redes? Dilemas da análise social da técnica. In: R. Pedro (2008, Maio). Redes e controvérsias: ferramentas para uma cartografia da 
dinâmica psicossocial. Anais do VII Esocite, Jornadas latinoamericanas de Estudos Sociais, Rio de Janeiro, RJ, Brasil. Recuperado em 15 Março de 2013, de http://www. necso. ufrj. br/esocite2008/resumos/36356. htm

Braga, M. L. M. (2009, Setembro). O jogo das narrativas: a prática do "si" e do mundo, pelos diários virtuais e outros ambientes narratológicos do game The Sims. Anais do II Encontro dos Programas de Pós-graduação em Comunicação de Minas Gerais, Belo Horizonte, MG, Brasil. Recuperado em 20 de Fevereiro, 2013, de http://www.fca. pucminas.br/embriao/textos/ojogodasnarrativasMarcosBraga.pdf

Brasil. (2006). Lei n. 8.069, de 13 de Julho de 1990. Dispõe sobre o Estatuto da Criança e do Adolescente. Brasília, DF: Ministério da Saúde. Recuperado em 18 de Junho de 2014, de http://bvsms.saude.gov.br/bvs/publicacoes/lei_8069_06_0117 M.pdf

Bunchät, G. (1996). O conceito de projeção e sua relação com os testes projetivos. Revista do Círculo Brasileiro de Psicanálise, 3, 22-27. Rio de Janeiro.

Calvalcante, L. I. C., Magalhães, C. M. C, \& Pontes, F. A. R. (2007). Abrigo para crianças de 0 a 6 anos: um olhar sobre as diferentes concepções e suas interfaces. Revista Mal-Estar e Subjetividade, 7(2), 329-352.

Colen, E. M., \& Queiroz e Melo, M. F. A. (2010). Os avatares como mediadores no jogo de papeis. Revista Pesquisas e Praticas Psicossociais, 5(1), 17-29. São J oão del-Rei.

Cruz, D. M., \& Krüger, F. L. (2004). O fascínio da simulação da vida: por que as crianças jogam (e gostam) do game The Sims. Famacos, 1(23), 59-69. Porto Alegre. Recuperado em 25 de Setembro, 2013, de http://200.144.189.42/ojs/index.php/famecos/article/viewArticl e/367

Fonseca, A. L. B, \& Mariano, M. S. S. (2008). Desvendando o mecanismo da projeção. Revista Psicologia Em foco, 1(1), 1-8. Recuperado em 14 Abril, 2013, de http://linux. alfamaweb.com.br/sgw/downloads/161_063102_10 .pdf

Huizinga, J. (1993). Homo Ludens (4a ed). São Paulo. Perspectiva.

Kastrup, V. (2012) Fazendo psicologia no campo da saúde mental: as oficinas de tecnologia e tecnologias sociais. In C. Maraschin, M. Simone, \& A. L. Palombini (Orgs.). Tecnologias em rede: oficinas de fazer saúde mental. (pp.173-177). Porto Alegre. Sulina.

Krüger, F. L., \& Cruz, D. M. (2001). Os jogos eletrônicos de simulação e a criança. Anais do Congresso Brasileiro da Comunicação, Campo Grande. Sociedade Brasileira de Estudos 
Interdisciplinares da Comunicação. Campo Grande. Recuperado em 12 de abril, 2013, de http://www. portcom. intercom.org. br/pdfs/13807053341644679 9996506862271941517747.pdf

Krüger, F. L., \& Cruz, D. M. (2004). Jogos (virtuais) de simulação da vida (real): a geração $Y$ e o The Sims. Anais Eletrônicos do XXVII INTERCOM - Congresso Brasileiro de Ciências da Comunicação, Porto Alegre.

Latour, B. (2000). A ciência em ação: como seguir cientistas e engenheiros sociedade afora. São Paulo: Ed. UNESP.

Latour, B. (2012) Reagregando o social: uma introdução à Teoria Ator-Rede. Salvador: Edufba.

Maia, A., \& Serafim, S. (2011). Análise da Teoria Ator-Rede (TAR) e sua relação com os paradigmas de Relações Públicas. Revista Contemporânea: Políticas públicas e o patrimônio histórico: das primeiras ações a economia da cultura, 9(1), 123-137.

Mol, A. (2007). Política ontológica. Algumas idéias e várias perguntas. In: Pedro, R. (2008). Redes e controvérsias: ferramentas para uma cartografia da dinâmica psicossocial. Anais do VII Esocite, Jornadas Latino-Americanas de Estudos Sociais. Rio de Janeiro. Recuperado em 19 de Maio, 2013, de http://www. necso.ufrj. br/esocite2008/resumos/36356. htm

Murano, E. (s/d) Conceito em disputa. Recuperado em 23 Agosto, 2012, http://revistalingua.uol.com.br/textos/67/artigo249097-1.asp

Parreira, S. M. C. P., \& Justo J. S. (2005). A criança abrigada: Considerações acerca do sentido da filiação. Psicologia em Estudo, 10(2), 175-180.

Pedro, R. (2008). Redes e controvérsias: ferramentas para uma cartografia da dinâmica psicossocial. Anais do VII Esocite, Jornadas latino-americanas de Estudos Sociais. Rio de Janeiro. Recuperado em 19 de Maio, 2013, de http://www. necso.ufrj. br/esocite2008/resumos/36356.htm

Pereira, H. C. (2007). O laboratório analítico: a psicologia de C.G. Jung examinada pela teoria do ator-rede. Tese de Doutorado, Universidade do Estado do Rio de Janeiro, Rio de Janeiro, RJ, Brasil.

Piaget, J. (1978). A Formação do Símbolo na Criança: imitação, jogo e sonho. (3a ed). Rio de Janeiro. Zahar Editores.

Pitta, C. (1991). Mônadas. In: Cabral, R.(Org.). Logos Enciclopédia Luso-brasileira de Filosofia (Vol. 3, pp. 93-932). São Paulo: Editora Verbo.

Tarde, G. (2007). Monadologia e sociologia - e outros ensaios (Trad: P. Neves). São Paulo. Cosac Naify.

Vygotsky, L. S. (1991). A Formação Social da Mente (4a ed). Rio de Janeiro: Martins Fontes. 
Werlang, B. S. G, Lima, G. Q., \& Fensterseifer, L. (2006). Teste Aperceptivo Familiar (FAT): Técnicas Projetiva de Avaliação Psicológica. In: Avaliação Psicológica, 5(2), 255-260. Recuperado em 10 de outubro, 2012, de http://pepsic.bvsalud.org/pdf/avp/v5n2/v5n2a18. pdf

\section{Endereço para correspondência Jéssica Maíres Severino Mota} Universidade Federal de São João del- Rei Praça Dom Helvécio 74, Fábricas, CEP 36301-160, São J oão del-Rei - MG, Brasil Endereço eletrônico: jessica.maires@gmail.com

\section{Marcos Vinícius Thomaz}

Universidade Federal de São João del- Rei Praça Dom Helvécio 74, Fábricas, CEP 36301-160, São J oão del-Rei - MG, Brasil Endereço Eletrônico: marcos_breze@yahoo.com.br

Maria de Fátima Aranha de Queiroz e Melo Universidade Federal de São J oão del-Rei, São J oão del-Rei, Brasil

Praça Dom Helvécio 74, Fábricas, CEP 36301-160, São J oão del-Rei - MG, Brasil Endereço eletrônico: fatimaqueiroz.ufsj@gmail.com

\section{Notas}

* Graduanda do curso de Psicologia da Universidade Federal de São João del Rei (UFS ), bolsista de Iniciação Científica Fapemig/UFSJ .

** Graduando do curso de Psicologia da Universidade Federal de São João del Rei (UFSJ ), bolsista de Iniciação Científica Fapemig/UFSJ

*** Docente da graduação e mestrado em Psicologia da Universidade Federal de São João del Rei (UFSJ), doutora em Psicologia Social pelo Programa de Pós Graduação em Psicologia Social (PPGPS) da Universidade do Estado do Rio de J aneiro (UERJ)

1 Tal como Agamben (2009) resgata de Foulcault, um dispositivo seria um “... conjunto decididamente heterogêneo comportando discursos, instituições, arranjos arquiteturais, decisões regulamentares, leis, medidas administrativas, enunciados científicos, proposições filosóficas, morais, filantrópicas, em resumo: tanto do dito como do não dito, eis os elementos do dispositivo. O dispositivo é, ele mesmo, uma rede que se estabelece entre estes elementos" (p. 9). Trata-se, portanto, de um conceito bastante próximo à idéia de rede postulada por Latour.

2 São imagens gráficas, geralmente em três D que, nos jogos eletrônicos, representam pessoas cuja criação é feita através das escolhas de roupas, sexo, características físicas (Colen \& Queiroz e Melo, 2010).

${ }^{3}$ Que envolvem execução ou manipulação dinâmica de um modelo de uma parte do mundo (Krüger \& Cruz, 2001).

4 Aqui estamos entendendo o jogo como um dispositivo que pode produzir subjetivações.

${ }^{5}$ Entendemos não humano, a partir da Teoria Ator-Rede, como tudo o que, não sendo humano, joga a favor da construção da nossa humanidade (Queiroz e Melo, 2011).

${ }^{6}$ As Casas Lares eram sentidas pelos participantes das oficinas como lugares em que os grupos eram instáveis em sua composição. Aqueles que eram os "melhores amigos" hoje se viam apartados pelas contingências de uma adoção ou de um retorno ao lar original, sem o devido anúncio aos companheiros. A equipe de cuidadoras também era instável, pois a rotatividade era constante. A "passagem" se apresentava como uma condição de atravessamento por tempo indeterminado, 
deixando dúvidas não apenas no "quem sou eu?", mas no "quem está comigo?" e no "com quem posso contar?"

7 Por serem tutelados, aqueles que viviam nas Casas Lares tinham sua rotina controlada e distribuída entre os vários projetos que freqüentavam como uma forma de enriquecer sua formação. Não podiam andar sozinhos. Eram sempre conduzidos por um motorista e acompanhados por uma cuidadora; não podiam conversar com estranhos, nem ter um Facebook, pois as coordenadoras das Casas receavam o risco de organizarem fugas e encontros não permitidos. Em relação a essas situações, os adolescentes reagiam com desagrado. Não Ihes cabia a identidade de "abrigados", nem as restrições que Ihes eram impostas.

8 Segundo Murano ( $/$ d), trata-se de um conceito ainda em disputa nos games studies, disciplina que estuda os jogos eletrônicos. A expressão vem do termo inglês gameplay ou playability, sendo utilizada por jogadores brasileiros para designar o quão jogável é um jogo, "se ele responde bem à interação dos jogadores", se lhes proporciona "uma experiência fluida e divertida", sem aborrecêlos com as facilidades ou dificuldades em excesso ( $s / p$ ) http://revistalingua.uol.com.br/textos/67/artigo249097-1.asp

${ }^{9}$ Figura tomada da informática que, na proposta de Latour (2006), significa aquilo que nos deixa acessar, visualizar, fazer conexões com quadros que fazem crescer as nossas possibilidades de ação.

10 O jogo não determinava qual o padrão de família era o mais adequado. $\mathrm{Na}$ versão The Sims 2, apenas colocava a condição de que houvesse "um adulto" (leiase um maior que pudesse exercer a função de um cuidador, um responsável). Convém destacar que o "ideal" de família buscado pelos participantes se remetia mais ao cuidado e ao afeto entre os participantes do que a qualquer outra maneira de nomear grupos ou relações (homo ou heteroafetivas, adultocêntricas ou não).

${ }^{11}$ Podemos nos remeter à semelhança deste movimento com a proposta dos testes projetivos utilizados em psicodiagnósticos em que se apresenta ao sujeito um material de estímulo ambíguo para que este lhe atribua livremente pensamentos e ações (Bunchaft, 1996).

${ }^{12}$ Definidas como uma unidade de todas as coisas que, inseridas na multiplicidade, refletiriam em si, de forma contracta, o universo (Pitta, 1991).

\section{Agradecimento}

Agradecemos à Fundação de Amparo à Pesquisa de Minas Gerais (FAPEMIG) que financiou esta pesquisa através do Edital 07/2013 de Extensão com Interface na Pesquisa, assim como através do Programa Institucional de Bolsas de Iniciação Científica (PIBIC/UFSJ). 